\title{
Measuring Marine Plastic Debris from Space: Initial Assessment of Observation Requirements
}

\author{
Víctor Martínez-Vicente ${ }^{1, *(\mathbb{D})}$, James R. Clark ${ }^{1}$ (D), Paolo Corradi ${ }^{2}$, Stefano Aliani ${ }^{3}$, \\ Manuel Arias ${ }^{4}$, Mathias Bochow ${ }^{5}{ }^{(D}$, Guillaume Bonnery ${ }^{6}{ }^{D}$, Matthew Cole ${ }^{1}$, Andrés Cózar ${ }^{7}$, \\ Rory Donnelly ${ }^{8}$, Fidel Echevarría ${ }^{7}$ D , François Galgani ${ }^{9}$ (D), Shungudzemwoyo P. Garaba ${ }^{10,11}$ (D), \\ Lonneke Goddijn-Murphy ${ }^{12}$, , Laurent Lebreton ${ }^{10}$, Heather A. Leslie ${ }^{13}$, \\ Penelope K. Lindeque ${ }^{1}$, Nikolai Maximenko ${ }^{14} \mathbb{D}$, François-Régis Martin-Lauzer ${ }^{4}$, \\ Delwyn Moller ${ }^{15}$, Peter Murphy ${ }^{16,17}$, Lorenzo Palombi ${ }^{18}$, Valentina Raimondi ${ }^{18}{ }^{1}$, \\ Julia Reisser ${ }^{19}$, Laia Romero ${ }^{20}$, Stefan G.H. Simis ${ }^{1}$ (D), Sindy Sterckx ${ }^{21}$ (D), \\ Richard C. Thompson ${ }^{22}$, Konstantinos N. Topouzelis ${ }^{23} \mathbb{D}_{\text {, Erik van Sebille }}^{24}$ ED, $^{\text {, }}$ \\ Joana Mira Veiga ${ }^{25}$ and A. Dick Vethaak 13,25
}

1 Plymouth Marine Laboratory, Prospect Place, Plymouth PL1 3DH, UK; jcl@pml.ac.uk (J.R.C.); mcol@pml.ac.uk (M.C.); pkw@pml.ac.uk (P.K.L.); stsi@pml.ac.uk (S.G.H.S.)

2 European Space Agency-ESTEC, Keplerlaan 1, Postbus 299, 2200 AG Noordwijk, The Netherlands; Paolo.Corradi@esa.int

3 ISMAR-CNR, Forte Santa Teresa, Pozzuolo di Lerici, 19032 La Spezia, Italy; stefano.aliani@ismar.cnr.it

4 ARGANS Ltd., Chamberlain House, 1 Research Way, Plymouth PL6 8BU, UK; marias@argans.co.uk (M.A.); FMartin-Lauzer@argans.co.uk (F.-R.M.-L.)

5 Section 1.4 Remote Sensing and Geoinformatics, Helmholtz Centre Potsdam-GFZ German Research Centre for Geosciences, Telegrafenberg, 14473 Potsdam, Germany; mathias.bochow@gfz-potsdam.de

6 Airbus Defence and Space-Space Systems 31, rue des Cosmonautes Z.I. du Palays, 31402 Toulouse, France; guillaume.bonnery@airbus.com

7 Dpto. Biología, Campus de Excelencia Internacional del Mar (CEIMAR), Instituto Universitario de Investigaciones Marinas (INMAR), Universidad de Cádiz, E-11510 Puerto Real, Spain; andres.cozar@uca.es (A.C.); fidel.echevarria@uca.es (F.E.)

8 European Association for Remote Sensing Companies (EARSC), Rue de la Loi 26, 1040 Brussels, Belgium; Rory.donnelly@earsc.org

9 IFREMER, LER/PAC, ZI Furiani, 20600 Bastia, France; francois.galgani@ifremer.fr

10 The Ocean Cleanup, Batavierenstraat 15, 4-7th floor, 3014 JH Rotterdam, The Netherlands; shungu.garaba@uni-oldenburg.de (S.P.G.); laurent.lebreton@theoceancleanup.com (L.L.)

11 Marine Sensor Systems Group, Institute for Chemistry and Biology of the Marine Environment (ICBM) Terramare, University of Oldenburg, Schleusenstr. 1, 26382 Wilhelmshaven, Germany

12 Environmental Research Institute, University of the Highlands and Islands, Castle Street, Thurso, Caithness KW14 7JD, UK; lonneke.goddijn-murphy@uhi.ac.uk

13 Dept. of Environment and Health, Vrije Universiteit Amsterdam, De Boelelaan 1085, 1081 HV Amsterdam, The Netherlands; heather.leslie@vu.nl (H.A.L.); dick.vethaak@deltares.nl (A.D.V.)

14 International Pacific Research Center, School of Ocean and Earth Science and Technology, University of Hawaii, Honolulu, HI 96822, USA; maximenk@hawaii.edu

15 Department of Electrical, Computer and Software Engineering, The University of Auckland, Auckland 1142, New Zealand; Delwyn.moller@auckland.ac.nz

16 Genwest Inc. 170 W. Dayton St. Suite 106A Edmonds, WA 98020, USA; peter.murphy@noaa.gov

17 Marine Debris Division, National Oceanic and Atmospheric Administration, 1305 East-West Highway, Silver Spring, MD 20910, USA

18 IFAC-CNR, Via Madonna del Piano 10, 50019 Sesto Fiorentino, Italy; l.palombi@ifac.cnr.it (L.P.); v.raimondi@ifac.cnr.it (V.R.)

19 Oceans Institute, University of Western Australia, Perth, WA 6009, Australia; jureisser@gmail.com

20 ISARDSAT, C. Marie Curie, 8-14, A213 08042 Barcelona, Spain; laia.romero@isardsat.cat

21 Remote Sensing Unit, Flemish Institute for Technological Research (VITO), Boeretang 200, 2400 Mol, Belgium; sindy.sterckx@vito.be 
22 International Marine Litter Research Unit, University of Plymouth, Drake Circus, Plymouth, Devon PL4 8AA, UK; R.C.Thompson@plymouth.ac.uk

23 Department of Marine Sciences, University of the Aegean, 81100 Mytilene, Greece; topouzelis@marine.aegean.gr

24 Institute for Marine and Atmospheric research, Utrecht University, PO Box 80125, 3508 TC Utrecht, The Netherlands; e.vansebille@uu.nl

25 DELTARES, 2600 MH Delft, The Netherlands; Joana.Veiga@deltares.nl

* Correspondence: vmv@pml.ac.uk; Tel.: +44-0-1752633461

Received: 29 July 2019; Accepted: 10 October 2019; Published: 21 October 2019

\begin{abstract}
Sustained observations are required to determine the marine plastic debris mass balance and to support effective policy for planning remedial action. However, observations currently remain scarce at the global scale. A satellite remote sensing system could make a substantial contribution to tackling this problem. Here, we make initial steps towards the potential design of such a remote sensing system by: (1) identifying the properties of marine plastic debris amenable to remote sensing methods and (2) highlighting the oceanic processes relevant to scientific questions about marine plastic debris. Remote sensing approaches are reviewed and matched to the optical properties of marine plastic debris and the relevant spatio-temporal scales of observation to identify challenges and opportunities in the field. Finally, steps needed to develop marine plastic debris detection by remote sensing platforms are proposed in terms of fundamental science as well as linkages to ongoing planning for satellite systems with similar observation requirements.
\end{abstract}

Keywords: remote sensing; marine plastic debris; mission requirements; hyperspectral sensors; multispectral imagers; high spatial resolution; sensors synergy; submesoscale processes

\title{
1. Introduction
}

The ocean receives solid waste from human activities, distributing the load widely, but not evenly. Accumulation of marine debris impacts marine life, but these areas are not well mapped globally nor are the causes well understood. To monitor impact and to improve our understanding, global observations are required.

Typically, synthetic polymers (i.e., plastics) constitute most of the discarded solid waste [1] entering the ocean every year [2,3]. This is reflected in surveys of marine debris, which frequently identify plastic as the major component [4], contributing from $60 \%$ to $80 \%$ of the total marine debris [5], with varying polymer chemical compositions in the different marine environments [6]. Impacts to marine life depend on the concentration and size of plastic debris and on the vulnerability of the system $[7,8]$.

Despite the growing body of experimental evidence regarding encounters between marine organisms and marine plastic debris $[9,10]$, much uncertainty surrounds the spatio-temporal distribution of plastic and the global marine budget [11,12]. Marine plastic debris is tied to plastic production, which has grown exponentially over the last 70 years, from 1.7 million tonnes in 1950 to 322 million tonnes in 2015 [13]. It is estimated that between 4.8 and 12.7 million metric tonnes of plastic entered the ocean from terrestrial sources in 2010 alone [3], with rivers contributing to 1.15 and 2.41 million tonnes of plastic waste [14]. However, a small fraction of those inputs, around 269 thousand metric tonnes, is found floating at or near the surface of the ocean [15]. This large mass-imbalance raises fundamental questions about the sources, pathways, sinks and processes which have been summarised by previous studies [8,16-19]:

- Question 1 (Q1): What are the magnitude, location and temporal variability of the sources and pathways into the marine environment of marine plastic debris? 
- Question 2 (Q2): What are the abundance, horizontal distribution and composition of marine plastic debris, and how do these attributes change over time?

- Question $3(\mathrm{Q} 3)$ : Where does marine plastic debris tend to accumulate?

- Question 4 (Q4): How is marine plastic debris transported and what are the dominant physical processes influencing its fate?

- Question 5 (Q5): What role do biological, chemical and photochemical interactions play in controlling the movement and degradation of marine plastic debris?

At present, our ability to address these questions globally is hampered by the limited availability of in situ observations which in turn is being held up by the lack of standardised sampling and analysis methodologies.

As a concept, a global observation system for marine debris would comprise several Earth Observation (EO) components, including: citizen science based, in situ and remote sensing from different platforms (satellites, aircraft or drones) [20]. Remote sensing satellites are designed to provide observations of global scope, continuous temporal coverage and harmonised data collection and processing, thus potentially being ideal tools for global marine debris monitoring. Ultimately, the development of a global indicator for marine plastic debris from satellite in the context of the UN Sustainable Development Goals (SDG 14, in particular 14.1.1) would be desirable.

The aim of this paper is to provide the first iteration to define a satellite remote sensing element for monitoring marine plastic debris, following standard methodology [21,22]. An important part of this process is the constraint of observational requirements. One such requirement is the identification of physico-chemical properties and their relation to a detectable signal from space. Hartmann et al. (2019) [23] have recommended criteria that define marine plastic and microplastic debris. The first criterion is chemical composition: for an object to be classed as marine plastic debris it has to contain synthetic or heavily modified natural polymers as essential ingredients. Other criteria specify that the marine plastic debris should be solid and non-soluble in water. Size, shape and structure, colour and origin are additional characteristics, but not essential qualifying properties.

Following this recommendation, the observable property for a remote sensing system should be based on the modification of the electromagnetic radiation spectrum signature due to the chemical signature of polymers. We review in this paper the spectral signature from plastic and its relevance to potential for detection from space. Secondary identification could be obtained by shape and structure, but these are properties that may change with size. By targeting a particular type of chemical compound, it is implied the expectation to separate the signature of plastics from all other kind of debris, whether man-made (e.g., glass, metal, wooden composites) or natural (e.g., natural wood), as well as non-debris structures (e.g., vessels).

The definition of sampling requirements (i.e., how often and with what spatial resolution) is also needed during the design of a remote sensing system. This is defined in relation to the time and spatial scales typical of the relevant oceanographic processes. Sampling requirements are usually formulated as threshold (or the "minimum" values required for the success of the system) and goal requirements (or "ideal" values which would be useful to advance the state of current knowledge). These values refer to answering the science questions, but could be relaxed due to practical or cost limitations in successive iterations $[24,25]$. Further iterations are expected before values are chosen to ultimately become the engineering specifications of an EO system.

Once the sampling requirements for remote sensing of marine plastic debris from satellites are defined, they need to be compared with current capabilities, to signal potential suitability and knowledge gaps. A mature satellite observing system, covering multiple spatial scales and application domains, already exists (e.g., Copernicus Sentinel fleet and VIIRS and Landsat series), and it is necessary to examine its potential for monitoring marine plastic pollution before looking into new solutions.

We review to what extent current and planned remote sensing technology matches the spatial and temporal scales required for marine plastic debris observations, highlighting their capabilities and limitations and the physico-chemical properties that are targeted. It is important to emphasise that 
the sampling requirements discussed here do not include requirements on sensitivity and accuracy of a potential sensor.

The recommendations derived from this analysis aim to guide subsequent scientific investigations as well as making a call for the wider concerted science policy effort needed to support the inclusion of marine plastic debris requirements in ongoing and future new remote sensing programs.

The results presented were derived from discussions during a workshop organised by the European Space Agency, ESA (30 November-1 December 2017, Noordwijk, The Netherlands). The workshop, which included researchers in the field of marine debris and experts from multiple areas of Earth Observation, continues international efforts to define sampling requirements for marine debris from satellites [18] and supports the wider efforts towards an integrated marine debris observing system [20].

\section{Processes Controlling Marine Plastic Debris Relevant to Satellite Remote Sensing}

The processes examined were limited to those that help answering scientific questions Q1, $\mathrm{Q} 2$ and Q3. Several physical and biological processes can affect the dispersion and accumulation of marine plastic debris and a full review of those is beyond the scope of this work. To make the problem manageable, the approach was to select only processes that could increase the potential for detection using satellite remote sensing. This meant to identify processes leading to accumulation of marine plastic debris close to the surface of the water or coastline, where they are also relevant for socio-economic reasons [8,17]. After these filters were applied, a list of processes emerged (Table 1).

Sources and pathways of input of marine plastic debris (Question 1, Q1) to the coastlines and upper ocean are land based (waste water discharges), maritime (fishing and aquaculture, shipping, passengers and crew on ocean vessels) or common to both (lost pellets, catastrophic events and improperly managed waste) [8]. Numerical modelling has identified that rivers are a primary pathway for plastics into the coastal ocean [14], with monitoring standards for marine plastic debris only beginning to appear in the literature [26,27].

Frontal areas formed at the mouth of the rivers have been identified as areas of accumulation and strong biological activity [28]. River discharge can reach up to hundred kilometres for a maximum of a month. Conceptual models [29] propose different scales for different areas of the river plume. According to these models and based on observations, there are three areas [30]: tidal, recirculating and far-field plumes; with typical timescales of $\sim 0.5$ days, $\sim 2-3$ days and $\sim 1-10$ days respectively. The sampling scales proposed here are adapted to resolve variability closer to the river tidal area [24], although higher spatial resolution $(\sim 1-2 \mathrm{~m})$ has been proposed to monitor water quality further into the river [31].

Another source of plastic debris to the marine environment is the accidental spillage due to maritime transport activities. The magnitude of this source is largely unknown (Q1), but it is expected to increase with increasing shipping volumes [8,32]. The extent of the dispersion of marine plastic debris from accidental container loss is difficult to quantify [33]. Given the large uncertainties, only tentative rough orders of magnitude for scales of observation can be provided at the moment, on the basis of requirements for sampling from remote sensing for oil spill detection at source (see Table 4.1 in IOCCG N3 [24]).

The accumulation of debris on the shoreline, or beaching on the drift-line of maximum tidal height, is related to Q1 and Q3. Anthropogenic factors such as coastal tourism and marine activities, proximity to urban areas and river mouths $[34,35]$ as well as coastal currents, wind and wave action influence the accumulation of marine plastic debris on the shoreline [36].

There are few studies related to beaching of marine plastic debris on the shoreline, however, useful indications on the scales involved can be taken from sediment transport [37]. The maximum spatial extent could be defined by tractable modelling units for sediment transport of $\sim 1000 \mathrm{~km}$ and over a period of $\sim 10$ years [38]. Spatial and temporal sampling from remote sensing should be in the same order or better than in situ monitoring. Beach debris sampling is conducted at various sites 
around the world, through voluntary initiatives or beach monitoring programmes [39-42]. According to these methods quantification of marine debris should be carried out along $100 \mathrm{~m}$ of beach length [42]. However, the focus of these surveys is on a small stretch of coast and are, in many cases, done, at best, seasonally, which can result in limited trends of abundance and composition of debris. With regard to temporal resolution, standard protocols recommend that a beach should be monitored at least four times in a year. However, surveys at regular intervals of four weeks would make multi-year trend monitoring results more reliable than current monitoring frequencies, to avoid variations due to meteorological and tidal artefacts [43]. 
Table 1. Major marine processes affecting the fate of marine plastic debris and their relevance to identified scientific questions (See the Introduction section). Spatial extent and lifetime of processes are reported alongside corresponding spatial and temporal sampling requirements [44]. Sampling requirements are reported in terms of threshold levels, see text for definition.

\begin{tabular}{|c|c|c|c|c|c|}
\hline \multirow[b]{2}{*}{ Marine Process } & \multicolumn{2}{|r|}{ Spatial } & \multicolumn{2}{|r|}{ Temporal } & \multirow[b]{2}{*}{ Related to Question (Q) } \\
\hline & $\begin{array}{c}\text { Spatial } \\
\text { Extent (max) }\end{array}$ & $\begin{array}{c}\text { Required Spatial } \\
\text { Resolution of Observations }\end{array}$ & $\begin{array}{c}\text { Lifetime of } \\
\text { Process (max) }\end{array}$ & $\begin{array}{c}\text { Required Frequency of } \\
\text { Observations }\end{array}$ & \\
\hline River discharge & $\sim 100 \mathrm{~km}$ & $\sim 20 \mathrm{~m}$ & $\sim 1$ month & at least every $12 \mathrm{~h}$ & Q1 \\
\hline Spills & $\sim 100 \mathrm{~km}$ & $\sim 20 \mathrm{~m}$ & $\sim 1$ month & at least every $24 \mathrm{~h}$ & Q1 \\
\hline Shoreline accumulation & $\sim 1000 \mathrm{~km}$ & $\sim 20 \mathrm{~m}$ & $\sim 10$ year & at least every $30 \mathrm{~d}$ & $\mathrm{Q} 1, \mathrm{Q} 2, \mathrm{Q} 3$ \\
\hline $\begin{array}{l}\text { Submesoscale convergence } \\
\text { filaments }\end{array}$ & $\sim 10 \mathrm{~km}$ & $100 \mathrm{~m}$ & $\sim 10 \mathrm{~d}$ & at least every $24 \mathrm{~h}$ & Q2, Q3 \\
\hline
\end{tabular}


The dynamics of marine plastic debris in the upper ocean (Q2 and Q3) are typically studied at the global scale using models that describe the movement of small positively buoyant plastic particles (see Table 2 in Hardesty et al. (2017) [17]). Typically, these models have a horizontal spatial resolution of $1 / 12^{\circ}(\sim 10 \mathrm{~km})$ with daily or monthly outputs resolving processes at spatial scales from ocean gyres down to mesoscale eddies. At present, such models show disagreement up to a factor of 10 in their estimates of plastic abundance in the most frequently sampled areas with high concentrations of plastics, such as the Northern Pacific and Atlantic Gyres [12].

Most of the disagreement among models has been attributed to the lack of observations, even in the gyres. At smaller spatial scales than those resolved by current models (i.e., $<\sim 10 \mathrm{~km}$ ), it has been hypothesised that physical structures, i.e., submesoscale frontal convergence areas [45] can accumulate marine debris. Recent in situ experiments [46] have demonstrated that these structures produce accumulation and patchiness of flotsam. Detection and quantification targeting submesoscale frontal convergence filaments would provide new information for models, to reduce their uncertainties.

Table 1 summarises the link between questions, processes, their spatial and temporal scales and the observational requirements, while Figure 1 presents a graphical summary of the processes involved.

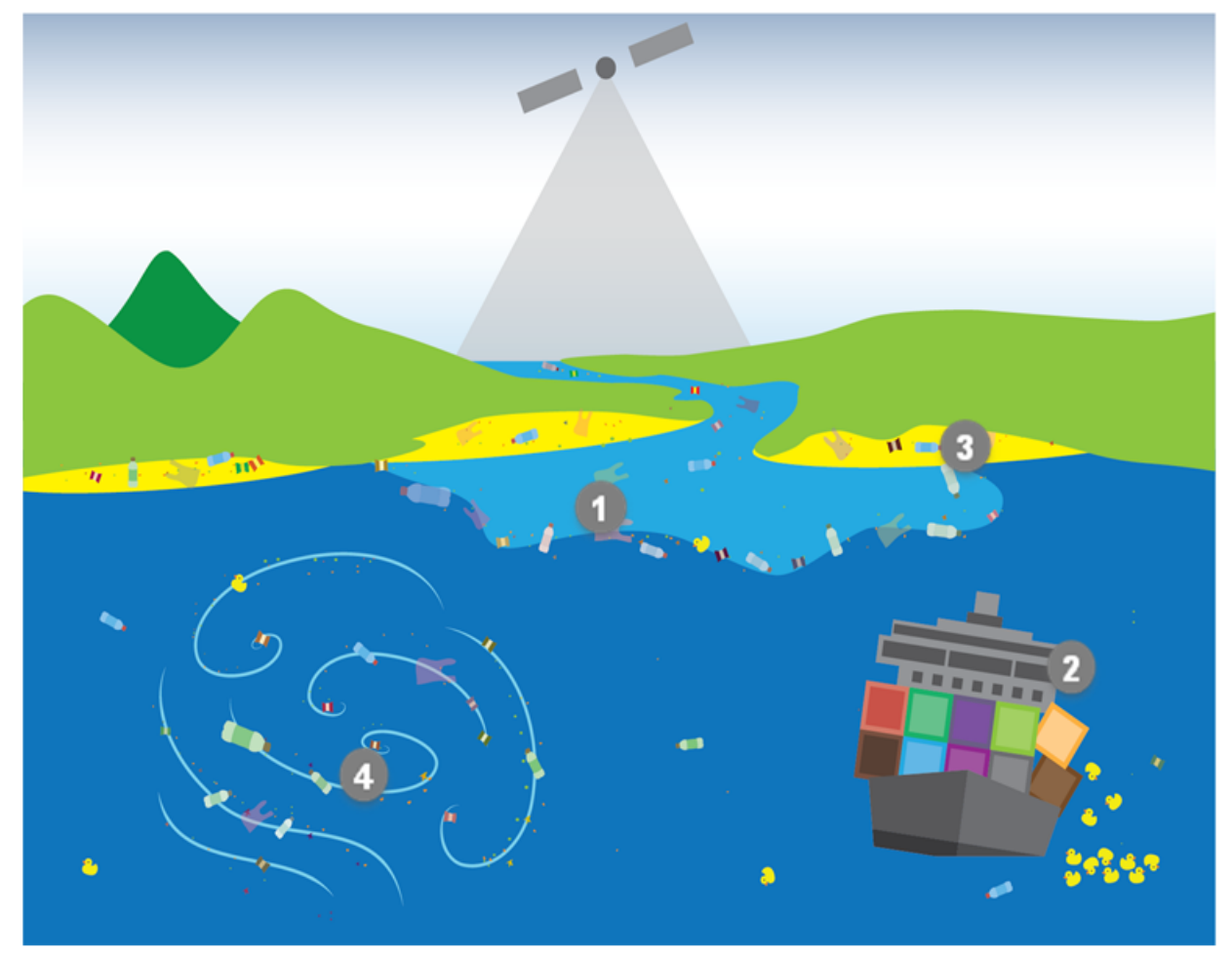

Figure 1. Diagram representing the four observational scenarios discussed in the text (Section 2). (1) River discharge, (2) spills, (3) shoreline accumulation, (4) submesoscale convergence filaments.

The greatest difference in sampling requirements is on the observation frequency. To resolve processes in coastal and oceanic environments, daily observations or at greater frequency are required to detect changes in accumulation areas driven by highly dynamic processes (river discharge, spills and submesoscale convergence filaments). Lower observation frequency (up to 30 day revisit) should be sufficient to monitor shoreline accumulation processes beyond the supratidal zone.

\section{Remote Sensing Methods with Potential for Marine Plastic Debris Detection}

A remote sensing method has detection potential if there is a direct relationship between the variable of interest and a feature of the detected signal. Passive optical methods considered here measure the visible (VIS, 400-700 nm) and near-infrared (NIR) to short-wave infrared (SWIR), i.e., 700-2500 nm parts of the spectrum; whereas active methods include laser-induced optical features 
(LIDAR) or radar, active in the microwave range [25]. Examples of each technology exist on proximal, airborne and satellite remote sensing platforms and are used routinely to monitor the surface layer of the ocean (i.e., few tenths of meters close to the surface, depending on the amounts of optically active substances). Despite their limitation to the upper ocean layer, it is relevant to discuss whether any of the remote sensing methods are able to uniquely attribute a relationship between the composition of plastic debris and a given radiometric property, under the definition of marine plastic debris adopted here [23]. Once the link to the property has been established, it is necessary to evaluate if any of the current or future missions can fulfil those measurements at the required observation scales to evaluate the gaps that need to be addressed.

\subsection{Passive Methods: Radiometry and Imaging Spectrometry}

Passive NIR to SWIR methods have recently demonstrated the potential for specific detection of marine plastic debris. These methods are similar to the hyperspectral features of hydrocarbons [47-49] and already in use for optical sorting of plastics in waste management and recycling. Specifically, for marine plastic debris, reflectance features have been recorded at around 1215 and $1732 \mathrm{~nm}$ [50].

Figure 2 illustrates the expected spectral reflectance features of plastic measured in those experiments, alongside the location of absorption features of aggregated marine-harvested small plastics. Over clear oceanic waters, hyperspectral measurements from an aircraft and linear spectral mixing modelling confirmed that distinct spectral features appear at 1215 and $1732 \mathrm{~nm}$ [51]. Measurements on a controlled experiment of various floating plastic debris items using a handheld hyperspectral radiometer show overall light reflectance decreases, and depths of the absorption bands decrease, with increasing transparency of plastic [52].

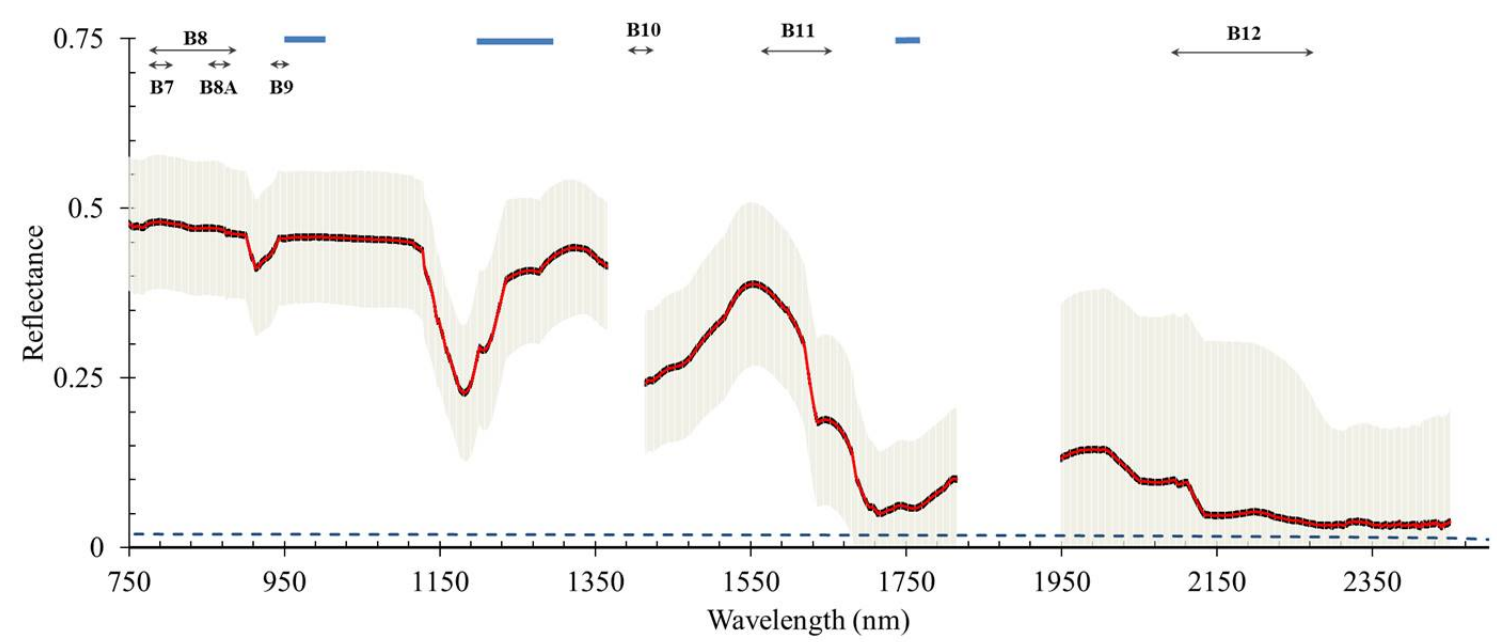

Figure 2. Near-infrared short-wave infrared (NIR-SWIR) reflectance spectrum (\%), plastic absorption feature locations and satellite detection windows. Thick solid red line is median reflectance spectrum and shadowed area is the standard deviation of all plastics measured (data adapted from [53]). Thick horizontal bars highlight the regions of the spectrum with major absorption features (data adapted from [50]). Double arrow end lines show the maximum width of the spectral response function and the band names of the Sentinel 2B Multi Spectral Imager (MSI). Dashed line is typical oceanic seawater reflectance shown for comparison (data corresponding to OPENOCEAN-SW2 spectra adapted from [54]).

SWIR features can be masked by a number of factors, the most important being water absorption. Garaba and Dierssen (2018) [50] reported a reduction of the median band depth index for wet versus dry plastics (using aggregated plastics) of $75 \%, 55 \%$ and $71 \%$ for 931,1215 and $1732 \mathrm{~nm}$ respectively. The high pure water absorption coefficient values for those wavelengths (i.e., 12,124 and $644 \mathrm{~m}^{-1}$ respectively [55]) not only attenuate the radiation through the atmosphere, but also reduce the light 
reflected back from the materials if they are wet. The absorption of water is not the only mechanism attenuating the reflected light from wet materials and further research is needed in this area (see Section 4). The expected differences in signals due to absence/presence of water on the marine plastics surfaces suggest different observation scenarios for dry and wet conditions. In addition to the intensity of the reflectance produced by the plastic, the width of the spectral features (thick horizontal lines in Figure 2) also constrains detection. The width of spectral features needs to be compared with the spectral responses of the different sensors.

Passive optical radiometers can be further classified according to the spectral resolution (i.e., capacity to resolve different wavelengths) of the instrument: pan-chromatic (high resolution optical imagers, capture the signal in the visible spectrum), multi-spectral (up to $\sim 20$ spectral bands) or hyper-spectral (more than $\sim 20$ spectral bands about 5-10 $\mathrm{nm}$ width). Extensive reviews of current and planned radiometric-based multispectral and hyperspectral missions exist in the literature [56,57]. Here we focus on passive optical radiometric missions with wavelengths close to the proposed detection bands for marine plastic debris reported above. Passive microwave radiometers could represent another way of detection of accumulation of debris, as it is currently done for oil films on water, but they are not further discussed here.

Table 2 summarises spatial, temporal and spectral resolution around the NIR and SWIR region relevant to marine plastic debris detection for current and some planned sensors. None of the current or planned sensors explicitly target marine plastics, however, it is useful to compare their sampling characteristics or requirements (if in planning phase) with the scales of the marine plastic debris problem in Table 1.

Table 2. Summary of satellite sensors and their spectral, spatial and temporal resolution characteristics. Near-infrared (NIR) bands listed close to those proposed for marine plastic debris detection. Spatial resolution is described by the size on the ground (ground sampling distance, GSD) of the minimum data unit. Temporal resolution is described by time between measurements over a given location. In italics, missions in different stages of planning, not launched yet.

\begin{tabular}{cccc}
\hline Sensor & NIR Bands (nm) & $\begin{array}{c}\text { Spatial Resolution } \\
\text { (GSD in m) }\end{array}$ & $\begin{array}{c}\text { Revisit Time } \\
\text { Interval (in days) }\end{array}$ \\
\hline OLCI (Sentinel-3) & $900 ; 1020$ & 300 (max) & 1 \\
\hline PACE & $\begin{array}{c}940 ; 1038 ; 1250 ; 1378 ; \\
1615 ; 2130 ; 2260\end{array}$ & 1000 & 2 \\
\hline $\begin{array}{c}\text { MSI (Sentinel-2) and } \\
\text { OLI (Landsat-8) }\end{array}$ & $\begin{array}{c}1373 ; 1613 ; 2202 \\
\text { PRISMA }\end{array}$ & 10 (max) & 7 to 14 \\
\hline ENMap & SWIR I (950-1390) & 30 & 4 \\
\hline SWIR II (1480-1760) & 30 & 4 \\
\hline SWIR III (1950-2450) & & 16 \\
\hline HySPIRI & 920 to 2500 & 10 & 3 to 5
\end{tabular}

High spatial resolution instruments provide spatially detailed images of the Earth surface. Their ground sampling distance (GSD, distance between the centres of pixels on the ground) is small in panchromatic mode (a single waveband), in the range of $25-30 \mathrm{~cm}$ (as in the so-called high spatial resolution imaging camera). Spectrally, an increasing number of private sector-funded sensors with sub-metre resolution are rapidly appearing with multispectral capabilities also in the visible, NIR and SWIR (e.g.,: Worldview-3 is Multispectral Nadir: 1.24 m; SWIR Nadir: 3.70 m, but commercial delivery at $7.5 \mathrm{~m}$ resolution). This increases the information content that may be derived from the imagery (including the ability for land cover classification) and allows corrections to be made, for example, 
for the effects of atmospheric water vapour on the measured surface parameters. Like all passive radiometric techniques, they require clear sky and daylight to collect data.

Ocean colour radiometers (e.g., OLCI on board Sentinel-3 or VIIRS on Suomi NPP) are now mature tools for global monitoring of optically active biogeochemical properties. Their original design requirements were driven by ocean climate science, and included also marine ecosystems monitoring, coastal water quality and dynamics of the upper ocean [58]. Accordingly, spatial and temporal observation scales match large-scale oceanic processes (seasonal and mesoscale processes), but not short-scale spatial and temporal variability (Table 1). Spectrally, near-infrared bands in OLCI are dedicated to water vapour absorption, vegetation and atmospheric correction and do not match the proposed spectral bands for marine plastic debris. The planned NASA mission PACE has a sensor with a matching band at $1250 \mathrm{~nm}$ [59], but investigations are needed to ascertain its potential for marine plastic debris. At a finer spatial resolution than OLCI, the Multi-Spectral Imager (MSI), available on Sentinel 2A and 2B, was designed for land monitoring applications. Figure 2 shows the spectral response function of Sentinel 2B MSI overlaid onto a typical reflectance spectrum of marine plastics. The spatial and temporal observation scales of Sentinel-2 MSI match shoreline monitoring requirement for plastic debris accumulations. The band centred at $1610 \mathrm{~nm}$, originally intended for snow/ice/cloud detection, or vegetation moisture stress assessment, does not overlap with the measured band centred at $1732 \mathrm{~nm}$ (Figure 2). However, initial results suggest it could be used for marine plastic debris detection. Topouzelis et al. (2019) [60] deployed three targets made out of different plastic materials and obtained matching imagery from Sentinel-2 MSI, finding an overall increase in the intensity of reflected light across the spectra from all targets even submerged in seawater, though large differences in the SWIR bands were due to different atmospheric correction algorithms. This highlights that further investigation should be dedicated to characterise the origin of the signal in Sentinel-2 MSI around $1732 \mathrm{~nm}$.

A number of hyperspectral imager spectroscopy missions are in various stages of development [56] with expected spectral resolution matching the wavelengths of potential features for marine plastic debris detection. The main foreseen applications for these sensors are vegetation, agriculture [61], soil, geology, disaster monitoring, land use change and water resources monitoring [62]. Compared to Sentinel-2 MSI, spatial resolution of hyperspectral imagers is coarser and temporal revisiting frequencies are lower. However, hyperspectral imagers cover a wide spectral range and have a fine spectral resolution (e.g., PRISMA has a band width less or equal to $12 \mathrm{~nm}$ ), with potential to capture plastic debris spectral features, that needs further investigation.

\subsection{Active Sensors: LIDAR and RADAR}

LIght Detection And Ranging (LIDAR) systems are active sensors that have been deployed from ships and aircraft for characterizing ocean properties. Depending on the technique used (based on elastic or inelastic processes), LIDAR applications include bathymetry, inherent optical properties of water, oil pollutants, coloured dissolved organic matter, phytoplankton and zooplankton content [63-66].

LIDAR systems have distinct advantages over passive systems of ocean colour radiometry: they can be used day and night, at low solar angles, and can provide depth-resolved information through the water column. LIDAR techniques based on inelastic processes such as fluorescence or Raman scattering represent particularly promising remote sensing techniques for plastic identification [67-69].

For atmospheric science, the primary instrument on the CALIPSO satellite, launched in 2006, is the Cloud-Aerosol LIDAR with Orthogonal Polarization (CALIOP) sensor, and it has reliably collected global LIDAR measurements for the past 10 years. This sensor has a spatial footprint of $100 \mathrm{~m}$, and initial efforts to adapt it for marine micro-particles have shown promising results by being able to retrieve the optical backscattering of particles [70].

A traditional radar system transmits an electromagnetic signal and records properties of the reflected signal from the scene. A distinct advantage of radars is the ability to operate independent 
of solar illumination, and in the presence of cloud cover (at frequencies $<95 \mathrm{GHz}$ ). Radar has a long heritage in remote sensing of oceanic conditions, e.g., scatterometry for wind/wave fields and altimetry for geostrophic currents. Such measurements tend to have $\mathrm{km}$-scale resolutions and have demonstrated their capacity to indirectly track potential accumulation areas for plastics, by providing information on ocean currents and wind speeds [71,72].

Higher resolution imaging radars are able to produce meter-scale resolution typically through synthetic aperture radar (SAR) processing. Meter-scale pixel resolution can be obtained depending on range and aperture synthesis length and scene correlation time. SAR sensors are capable of detecting surfactants such as biogenic films and oil slicks, and targets such as derelict fishing gear and larger items [73-77] by exploiting both intensity and polarimetric features of the backscattered signals. However, the particularities in composition and size of marine debris and their interaction with the background ocean make direct detection exploiting SAR very challenging. Though applicable to both the coastal and open oceans, mission configuration and optimization for sensor sensitivity and spatio-temporal sampling must be considered. New paradigms in platforms and observational scenarios may alleviate some of the typical constraints between swath-coverage, sensitivity and radar ambiguities. The proliferation of smallSats enabling constellations of sensors holds the promise to bring broader coverage and/or faster revisit with multiple limited-swath sensors on multiple platforms (e.g., https:/ / www.capellaspace.com,https:/ / umbralab.com,https:/ /www.iceye.com/). Shore, ship and air-borne demonstrations are planned with the goal to quantify limits of detectability and a goal of sub-pixel (decimetre scale) detection.

Of the remote sensing methods reviewed here, passive methods that cover the SWIR offer potential for plastic debris detection. In particular, due to absence of water, to narrow spectral bands, to extended spectral coverage and to high spatial and temporal resolution, the planned hyperspectral sensors fulfil sampling requirements on the shore (Table 1). In contrast, there are no current or planned sensors that match the high spatial resolution and high sampling frequencies needed for the water scenarios (i.e., river discharge, spills or submesoscale convergence filaments), opening a range of exciting questions to research.

\section{Challenges and Opportunities for Remote Sensing Detection of Marine Plastic Debris}

Gaps in research have emerged after evaluating the suitability of current remote sensing methods to the specific problem of marine plastic debris. These gaps are related to: (1) the fundamental relationship between the marine plastic composition and remote sensing reflectance and (2) to the proposed scales of observation. This discussion focuses on breaking down these two questions into tractable units (challenges) and proposing ways forward (opportunities).

There is initial evidence that the presence of plastic particles modifies remote sensing reflectance in the NIR-SWIR spectral region with respect to water [50]. Water strongly absorbs light in the NIR-SWIR but absorption in a thin film of water cannot explain all suppression of light reflectance of wet plastic [52]. Lekner and Dorf (1988) [78] described other mechanisms that contribute to the weakening of light reflectance at a wet surface. For finely divided media, when the interstitial space in the medium is filled with water, enhanced forward scattering and reduced backscattering occurs. This would explain why materials such as aggregated sand and microplastics look darker when wet. For solid rough surfaces (macroplastics), the higher refractive index of water than of air better explains the reduced reflectance by a thin film of water as it causes a fraction of diffuse reflected light at the plastic to totally reflect back down at the water-air interface. The rougher the surface, the more diffuse reflection, and thus the more total internal reflection at the water-air interface. More recent measurements of the bidirectional reflectance [79] have added to those mechanisms the microscopic roughness of individual particles, which further enhances the attenuation due to an increased capacity to trap water. None of these studies have been specific to plastics or in the NIR-SWIR part of the spectra, hence additional laboratory investigations are needed. 
However, in addition to water, other materials with similar chemical composition to marine plastic debris can cause similar interference and their specific contribution to the signal needs to be separated. For example, non-photosynthetic plant matter, with high content in natural polymers such as lignin and cellulose, also has spectral absorption features in the proximity of the plastic absorption wavebands [80]. In addition, the effect that colonization of plastic debris by biological agents has on the spectral absorption around the wavebands of interest is not yet known.

Additional to contamination of the signal by other substances is the contamination from the environment. On the shoreline, the plastic debris signal can be masked by underlying and surrounding matter, whereas marine plastic debris floating in coastal and oceanic waters sunglint [81], whitecaps [82], bubbles [83] and high suspended sediment concentrations [84] affect reflectance at wavelengths greater than $1000 \mathrm{~nm}$. Some of the planned hyperspectral sensors have greater signal-to-noise ratio (SNR) across the spectra than, for instance, MSI on Sentinel-2. For instance, for floating Sargassum, it has been estimated that for radiances typical from clear waters, an SNR of 200:1 could be sufficient for detection of pixels covered at least a 20\% with Sargassum [85]. Unique spectral features in VIS and NIR can be exploited for Sargassum detection, and the challenge is to confirm whether the spectral features observed in the laboratory for plastic can be detected with concentrations recorded in situ.

If progress in the definition of characteristics of a remote sensing system is to be made, fundamental investigations must be carried out to quantify the relative contributions to the radiative transfer at the air-sea interface by the different sources, including marine plastic debris. We can thus formulate the first research challenge as follows:

- Challenge 1: to define the SNR for spectroradiometric detection of marine plastic debris.

- Opportunity 1: to sample marine plastic debris in target scenarios (e.g., those in Table 1 and Figure 1) with simultaneous chemical and optical characterisation and/or perform controlled experiments and radiative transfer modelling at the air-sea interface with expected realistic situations.

Low sampling frequency (Table 1) and limited knowledge of the water attenuation effects on the NIR and SWIR are identified requirements for satellite observations at the shoreline scenario. From the review of optical techniques, detection of marine plastic litter on the shoreline (above the tidal line) appears, at present, more feasible than in the water scenarios. Multispectral and hyperspectral imagers have sampling frequencies and spectral coverage and resolution suitable for detection. Figure 3 shows a plastic target on a beach in the UK, observed from Sentinel-2B MSI. Preliminary results from this experiment (not shown here) indicate that the brightness of the non plastic matter surrounding the targets over land affects the retrieval of targets that are smaller than the ground sampling distance, as predicted by modelling studies on the effect of subpixel shapes on land detection indices for Sentinel-2 MSI [86]. 

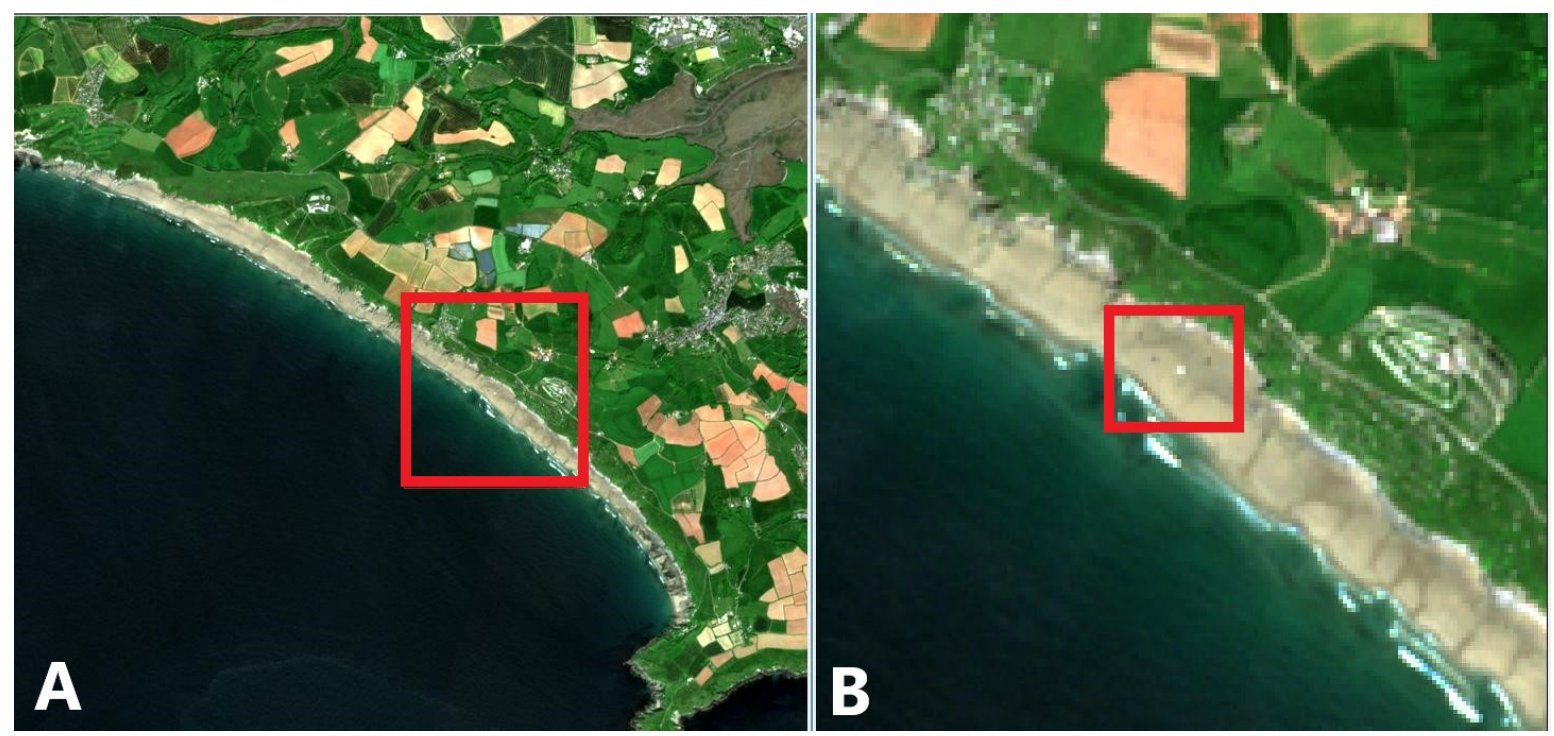

Figure 3. Example of plastic debris detection experiment during a Sentinel-2B overpass on 15 May 2018 over Whitsand Bay (United Kingdom). (A) Overview of the bay area with the study area indicated by a red square, shown in detail in $(\mathbf{B})$ with the positions of the plastic targets $(10 \times 10 \mathrm{~m})$ visible within the red square.

It is very likely that with the advent of hyperspectral imaging spectroscopy from space (EnMap, PRISMA, SHALOM, HyspIRI or HYPXIM sensors), the synergy between hyperspectral and multispectral images can be used to enrich co-located images. Acuña-Ruz et al. (2018) [87] demonstrated that a combination of in situ quantification using hyperspectral radiometric measurements with very high spatial resolution imagers $(1 \mathrm{~m})$ could be used for remote quantification of marine plastic debris on a beach. Guanter et al. (2018) [88] have recently reviewed the techniques and potential for synergy between hyperspectral imagers, multispectral imagers, ocean colour radiometry and LIDAR techniques. Further studies on how these synergies can be exploited for land/shore accumulation of marine plastic debris should be addressed:

- Challenge 2: to evaluate remote sensing capabilities on the shoreline.

- Opportunity 2: to exploit synergy between high spectral resolution and high spatial resolution current and planned remote sensing methods.

Because of the highly dynamic nature of the processes in the marine environment controlling the fate of marine plastic debris (Table 1), there is no clear match with the current or planned radiometric missions. Ocean colour radiometry with higher sampling frequency and higher sensitivity is well adapted for the low levels of reflectance in the ocean. However, the spatial resolution available for satellite ocean colour radiometers $(300 \mathrm{~m})$ is still coarse for detection of relatively small footprint events such as spills and submesoscale convergence filaments.

Ocean colour radiometers could still be useful to detect large fronts formed around river discharges or large convergence filaments. Synergy studies between ocean colour radiometry and high spectral resolution have detected harmful algal blooms in coastal areas, thanks to the specific pigment assemblage and its related radiometric signal in the visible part of the spectrum [89]. Although common spectral features in the visible are not expected from marine plastic debris, changes in intensity of the reflected light could be exploited if in situ quantification and radiometry were available for validation $[85,90,91]$. Controlled experiments using artificial plastic targets on the sea surface could be used to gain a better understanding together with the construction of a specific dataset from in situ observations combining radiometric and marine plastic debris concentrations.

In addition to the potential contamination issues, there is the problem to separate the signal of marine plastic debris from non-debris plastic matter in use. A combination of methods, including ship positioning information [92] is in place for ship detection, and could be used for this task. 
- Challenge 3: to develop remote sensing methods to specifically detect floating marine plastic debris.

- Opportunity 3: indices to detect floating algae, in combination with other sources of information could be used to separate among floating objects.

Given that existing and planned instrument configurations fall short of meeting the specific requirements for plastic debris detection, a pragmatic programmatic approach to develop a system for marine plastic debris detection is needed. This could be achieved through synergy with other ongoing initiatives.

CEOS (2018) [93] defined requirements of spectral bands with $5 \mathrm{~nm}$ spacing between 360 and $1000 \mathrm{~nm}$ augmented by a shortwave infrared imaging spectrometer, which could also match marine plastic debris detection. Although there is no clear indication of the temporal observation scale in the CEOS recommendations, spatial resolutions proposed are between 17 and $33 \mathrm{~m}$ ground sampling distance, matching observation requirements for river discharge, spills and submesoscale convergence filaments. Requirements for satellite monitoring essential biodiversity variables in coastal ecosystems [94] were also similar to those listed in Table 1. Muller-Karger et al. (2018) [94] proposed that an observation system should be set up with high spatial, high spectral, high temporal and high radiometric sampling specifications (i.e., an $\mathrm{H} 4$ system). A spatial resolution of $30 \mathrm{~m}$ should be combined with a temporal frequency of sampling between hours and days, which matches most of the processes included here. A $5 \mathrm{~nm}$ spectral resolution in the visible, $10 \mathrm{~nm}$ resolution between 900-2500 nm or at least two or more bands with centres at 1030,1240, 2125 and $2260 \mathrm{~nm}$, were required mainly for atmospheric correction over turbid waters and wetland vegetation, but not explicitly including monitoring for marine plastic debris. In addition, a high radiometric quality is required (SNR above 800) based on signal levels typical of the open ocean, due to the wide range of reflectance in coastal areas, from very bright to very dark. Because these requirements are so close to those for marine plastic debris detection, it is important that communication occurs with teams in charge of mission development at the early stage so that objectives on marine plastic debris detection can be included in the final mission specifications.

- Challenge 4: to liaise with current mission planning to enhance the role of marine plastic debris detection in the requirements specifications.

- Opportunity 4: to coordinate development of the remote sensing system for marine plastic debris at an international level, such that the specific requirements can be fed at the initial stage of development of future observation systems.

\section{Conclusions, Implications and Recommendations}

We have identified the main processes relevant for marine plastic debris monitoring (Table 1) with a view to defining a set of observational (sampling) requirements. The temporal and spatial scales of processes were compared to those of sampling by current and planned observation techniques, to identify gaps and opportunities for development. Active sensor techniques have been reviewed, while our focus was on passive radiometric methods, their spectral resolution and characteristics, leaving radiometric sensitivity and accuracy to be addressed in future studies.

A separation between requirements for land/shoreline and in/on water has emerged from the review of the main processes controlling the fate of marine plastic debris (Table 1). This separation is due to the higher temporal variability of the processes controlling marine plastic debris floating or in water compared to those controlling marine plastic dynamics on the shore. In addition, when considering the spectral properties that could be exploited, it has been shown that water content can attenuate significantly the signal for marine plastic debris in the NIR-SWIR.

The implication of this result is that shoreline marine debris detection could potentially be addressed by exploiting the NIR-SWIR spectral features through a synergy of hyperspectral imaging spectroscopy and multispectral imaging at high spatial resolution and that this approach is ongoing in 
the land EO community. Future experiments, in situ measurements and modelling to validate this approach will have to combine quantitative measurement of plastics and their relationship to the spectral measurement to be able to derive quantitative indices from satellite observation.

For the water environment, there is a greater challenge than for shore-based (dry) detection in terms of signal available and temporal scales of observation. The extent of the signal available in the NIR-SWIR from current concentrations of marine plastic debris remains to be quantified. Experiments and in situ measurements of emerged and submerged marine plastic debris and associated radiometry should be conducted to explore the signal-to-noise ratio. River plumes frontal areas, opportunistic sampling of spills and sampling at filaments from submesoscale processes should be actively targeted as higher accumulation points.

Because of the novelty of this field of research, observation requirements for marine plastic debris have to date not been considered in new mission designs. However, as has been shown here, there is an overlap in terms of temporal, spatial and likely spectral requirements with both land and coastal missions that are currently being planned. This work should raise awareness to development teams of those missions, so that taking into account requirements for the monitoring of marine plastic debris at an early stage would help achieve a greater impact of new missions.

Author Contributions: Writing-original draft preparation, V.M.-V.; writing-review and editing, J.R.C., P.C., S.A., M.A., M.B., G.B., M.C., A.C., R.D., F.E., F.G., S.P.G., L.G.-M., L.L., H.A.L., P.K.L., N.M., F.-R.M.-L., D.M., P.M., L.P., V.R., J.R., L.R., S.G.H.S., S.S., R.C.T., K.N.T., E.v.S., J.M.V., A.D.V.; all authors contributed to discussions during workshop.

Disclaimer: The input, views, or opinions expressed by author P.M. in his contributions to this paper are those of the author and do not necessarily reflect the views of NOAA or the Department of Commerce.

Funding: Support by the ESA General Studies Programme to V.M-V., J.R.C., P.L., S.G.H.S. through OPTIMAL grant is acknowledged (project No. 4000120879/17/NL/PS). V.M-V., S.A., N.M. and E.v.S. are members of WG 153 supported, in part, from funding provided by national committees of the Scientific Committee on Oceanic Research (SCOR) and from a grant to SCOR from the U.S. National Science Foundation (OCE-1840868). E.v.S. is also supported by the European Research Council (ERC) under the European Union's Horizon 2020 research and innovation programme (grant agreement No 715386). S.P.G. is supported by funding from Forschungsgemeinschaft (DFG, German Research Foundation)-Projektnummer 417276871. A.C. and F.E. were supported by MIDaS project (CTM2016-77106-R, AEI/FEDER/UE). J.R.C. and P.K.L. were partially supported by NERC grant (NE/L003988/1). N.M. was partly supported by NASA through grants 80NSSC17K0559 and NNX17AH43G. Inputs from NM, DM, and PM were informed by the 2016 Workshop on Marine Debris Remote Sensing (http://iprc.soest.hawaii.edu/NASA_WS_MD2016/), partly supported by the NASA grant NNX15AT43G. ESA-General Studies Programme support for the 2017 ESA Workshop on Remote Sensing of Marine Litter is acknowledged.

Acknowledgments: This work is the result of discussions and contributions from the 2017 ESA Workshop on Remote Sensing of Marine Litter (30 November-1 December 2017, ESA-General Studies Programme, The Netherlands) which involved researchers in the field of marine debris and experts from multiple areas of Earth Observation. Thanks to D. Ashby for the artwork in Figure 1 and T. Platt for useful comments on the manuscript. We thank the comments of three anonymous reviewers who helped improve this manuscript.

Conflicts of Interest: The authors declare no conflict of interest. The funders had no role in the design of the study; in the collection, analyses, or interpretation of data; in the writing of the manuscript, or in the decision to publish the results.

\section{References}

1. Bergman, M.; Gutow, L.; Klages, M. Marine Anthropogenic Litter; Springer: Cham, Switzerland, 2015. [CrossRef]

2. Cole, M.; Lindeque, P.; Halsband, C.; Galloway, T.S. Microplastics as contaminants in the marine environment: A review. Mar. Pollut. Bull. 2011, 62, 2588-2597. [CrossRef] [PubMed]

3. Jambeck, J.R.; Geyer, R.; Wilcox, C.; Siegler, T.R.; Perryman, M.; Andrady, A.; Narayan, R.; Law, K.L. Plastic waste inputs from land into the ocean. Science 2015, 347, 768-771. [CrossRef] [PubMed]

4. Barnes, D.; Galgani, F.; Thompson, R.; Barlaz, M. Accumulation and fragmentation of plastic debris in global environments. Philos. Trans. R. Soc. B Biol. Sci. 2009, 364, 1985-1998. [CrossRef] [PubMed] 
5. Gregory, M.; Ryan, P. Pelagic plastic and other seaborne persistent synthetic debris: A review of Southern Hemisphere perspectives. In Marine Debris—Sources, Impacts and Solutions; Coe, J., Rogers, D., Eds.; Springer: New York, NY, USA, 1997; pp. 46-66.

6. Erni-Cassola, G.; Zadjelovic, V.; Gibson, M.I.; Christie-Oleza, J.A. Distribution of plastic polymer types in the marine environment; A meta-analysis. J. Hazard. Mater. 2019, 369, 691-698. [CrossRef]

7. Clark, J.R.; Cole, M.; Lindeque, P.K.; Fileman, E.; Blackford, J.; Lewis, C.; Lenton, T.M.; Galloway, T.S. Marine microplastic debris: A targeted plan for understanding and quantifying interactions with marine life. Front. Ecol. Environ. 2016, 14, 317-324. [CrossRef]

8. Law, K.L. Plastics in the Marine Environment. Annu. Rev. Mar. Sci. 2017, 9, 205-229. [CrossRef]

9. de Sa, L.; Oliveira, M.; Ribeiro, F.; Rocha, T.L.; Futter, M.N. Studies of the effects of microplastics on aquatic organisms: What do we know and where should we focus our efforts in the future? Sci. Total Environ. 2018, 645, 1029-1039. [CrossRef]

10. Gall, S.C.; Thompson, R.C. The impact of debris on marine life. Mar. Pollut. Bull. 2015, 92, 170-179. [CrossRef]

11. Cózar, A.; Echevarría, F.; González-Gordillo, J.I.; Irigoien, X.; Úbeda, B.; Hernández-León, S.; Palma, Á.T.; Navarro, S.; García-de Lomas, J.; Ruiz, A.; et al. Plastic debris in the open ocean. Proc. Natl. Acad. Sci. USA 2014, 111, 10239-10244. [CrossRef]

12. van Sebille, E.; Wilcox, C.; Lebreton, L.; Maximenko, N.; Hardesty, B.D.; van Franeker, J.A.; Eriksen, M.; Siegel, D.; Galgani, F.; Law, K.L. A global inventory of small floating plastic debris. Environ. Res. Lett. 2015, 10, 124006. [CrossRef]

13. PlasticsEurope. The Facts 2016 An analysis of European Plastics Production, Demand and Waste Data; Association of Plastics Manufacturers; Brussels, Belgium, 2016.

14. Lebreton, L.C.M.; van der Zwet, J.; Damsteeg, J.W.; Slat, B.; Andrady, A.; Reisser, J. River plastic emissions to the world's oceans. Nat. Commun. 2017, 8, 15611. doi:10.1038/ncomms15611. [CrossRef] [PubMed]

15. Eriksen, M.; Lebreton, L.C.M.; Carson, H.S.; Thiel, M.; Moore, C.J.; Borerro, J.C.; Galgani, F.; Ryan, P.G.; Reisser, J. Plastic Pollution in the World's Oceans: More than 5 Trillion Plastic Pieces Weighing over 250,000 Tons Afloat at Sea. PLoS ONE 2014, 9, e111913. [CrossRef] [PubMed]

16. Galgani, F. Marine litter, future prospects for research. Front. Mar. Sci. 2015, 2, 87. [CrossRef]

17. Hardesty, B.D.; Harari, J.; Isobe, A.; Lebreton, L.; Maximenko, N.; Potemra, J.; van Sebille, E.; Vethaak, A.D.; Wilcox, C. Using Numerical Model Simulations to Improve the Understanding of Micro-plastic Distribution and Pathways in the Marine Environment. Front. Mar. Sci. 2017, 4, 30. [CrossRef]

18. Maximenko, N.; Chao, Y.; Moller, D. Developing a remote sensing system to track marine debris. EOS 2016, 97. [CrossRef]

19. Ryan, P.G.; Moore, C.J.; van Franeker, J.A.; Moloney, C.L. Monitoring the abundance of plastic debris in the marine environment. Philos. Trans. R. Soc. B Biol. Sci. 2009, 364, 1999-2012. [CrossRef]

20. Maximenko, N.; Corradi, P.; Law, K.L.; Van Sebille, E.; Garaba, S.P.; Lampitt, R.S.; Galgani, F.; Martinez-Vicente, V.; Goddijn-Murphy, L.; Veiga, J.M.; et al. Toward the Integrated Marine Debris Observing System. Front. Mar. Sci. 2019, 6, 447. [CrossRef]

21. McClain, C.R.; Meister, G. Mission Requirements for Future Ocean Colour Sensors; IOCCG: Dartmouth, NS, Canada, 2012. [CrossRef]

22. Verstraete, M.M.; Diner, D.J.; Bézy, J.L. Planning for a spaceborne Earth Observation mission: From user expectations to measurement requirements. Environ. Sci. Policy 2015, 54, 419-427. [CrossRef]

23. Hartmann, N.B.; Hüffer, T.; Thompson, R.C.; Hassellöv, M.; Verschoor, A.; Daugaard, A.E.; Rist, S.; Karlsson, T.; Brennholt, N.; Cole, M.; et al. Are We Speaking the Same Language? Recommendations for a Definition and Categorization Framework for Plastic Debris. Environ. Sci. Technol. 2019, 53, 1039-1047. [CrossRef]

24. Sathyendranath, S. Remote Sensing of Ocean Colour in Coastal and Other Optically-Complex Waters; IOCCG: Dartmouth, NS, Canada, 2000. [CrossRef]

25. Robinson, I. Measuring the Oceans from Space: The Principles and Methods of Satellite Oceanography; Springer: Berlin/Heidelberg, Germany, 2004.

26. González-Fernández, D.; Hanke, G. Toward a Harmonized Approach for Monitoring of Riverine Floating Macro Litter Inputs to the Marine Environment. Front. Mar. Sci. 2017, 4, 86. [CrossRef] 
27. van Emmerik, T.; Kieu-Le, T.C.; Loozen, M.; van Oeveren, K.; Strady, E.; Bui, X.T.; Egger, M.; Gasperi, J.; Lebreton, L.; Nguyen, P.D.; et al. A Methodology to Characterize Riverine Macroplastic Emission Into the Ocean. Front. Mar. Sci. 2018, 5, 372. [CrossRef]

28. Acha, E.M.; Piola, A.; Iribarne, O.; Mianzan, H. Ecological Processes at Marine Fronts: Oases in the Ocean; Springer: Cham, Switzerland, 2015.

29. Horner-Devine, A.R.; Jay, D.A.; Orton, P.M.; Spahn, E.Y. A conceptual model of the strongly tidal Columbia River plume. J. Mar. Syst. 2009, 78, 460-475. [CrossRef]

30. Hickey, B.M.; Kudela, R.M.; Nash, J.D.; Bruland, K.W.; Peterson, W.T.; MacCready, P.; Lessard, E.J.; Jay, D.A.; Banas, N.S.; Baptista, A.M.; et al. River Influences on Shelf Ecosystems: Introduction and synthesis. J. Geophys. Res. Ocean. 2010, 115. [CrossRef]

31. Olmanson, L.G.; Brezonik, P.L.; Bauer, M.E. Airborne hyperspectral remote sensing to assess spatial distribution of water quality characteristics in large rivers: The Mississippi River and its tributaries in Minnesota. Remote Sens. Environ. 2013, 130, 254-265. [CrossRef]

32. World Shipping Council. Containers Lost at Sea-Update 2017; World Shipping Council: Washington, DC, USA, 2017.

33. Kremer, X. Projet Lostcont: Les conteneurs perdus par les navires dans le golfe de Gascogne et ses abords. Bull. d'information du Cedre 2009,25, 14-16.

34. Critchell, K.; Lambrechts, J. Modelling accumulation of marine plastics in the coastal zone; what are the dominant physical processes? Estuar. Coast. Shelf Sci. 2016, 171, 111-122. [CrossRef]

35. Hoellein, T.; Rojas, M.; Pink, A.; Gasior, J.; Kelly, J. Anthropogenic Litter in Urban Freshwater Ecosystems: Distribution and Microbial Interactions. PLoS ONE 2014, 9, e98485. [CrossRef]

36. Browne, M.A.; Galloway, T.S.; Thompson, R.C. Spatial Patterns of Plastic Debris along Estuarine Shorelines. Environ. Sci. Technol. 2010, 44, 3404-3409. [CrossRef]

37. Carter, R.W.G. Coastal Environments: An Introduction to the Physical, Ecological, and Cultural Systems of Coastlines; Academic Press Limited: London, UK, 1995.

38. Giardino, A.; Schrijvershof, R.; Nederhoff, C.M.; de Vroeg, H.; Brière, C.; Tonnon, P.K.; Caires, S.; Walstra, D.J.; Sosa, J.; van Verseveld, W.; et al. A quantitative assessment of human interventions and climate change on the West African sediment budget. Ocean Coast. Manag. 2018, 156, 249-265. [CrossRef]

39. Lippiatt, S.; Opfer, S.; Arthur, C. Marine Debris Monitoring and Assessment; NOAA Technical Memorandum NOSORR46; National Oceanic and Atmospheric Administration: Silver Spring, MD, USA, 2013; p. 82.

40. Opfer, S.; Arthur, C.; Lippiatt, S. NOAA Marine Debris Shoreline Survey Field Guide; National Oceanic and Atmospheric Administration: Silver Spring, MD, USA, 2012; p. 15.

41. OSPAR-Commission. Guideline for Monitoring Marine Litter om Beaches in the OSPAR Area; OSPAR: London, UK, 2010.

42. TSG-ML. Guidance on Monitoring of Marine Litter in European Seas; Joint Research Centre: Ispra, Italy, 2013; p. 128.

43. Schulz, M.; Clemens, T.; Förster, H.; Harder, T.; Fleet, D.; Gaus, S.; Grave, C.; Flegel, I.; Schrey, E.; Hartwig, E. Statistical analyses of the results of 25 years of beach litter surveys on the south-eastern North Sea coast. Mar. Environ. Res. 2015, 109, 21-27. [CrossRef]

44. Martinez-Vicente, V.; Clark, J.R.; Lindeque, P.K.; Simis, S.G.H.; Donnelly, R. Application Analysis Report and Marine Litter Mission Requirements Document. V3.1; European Space Agency-ESTEC: Noordvijk, The Netherlands, 2019.

45. Taylor, J.R. Accumulation and Subduction of Buoyant Material at Submesoscale Fronts. J. Phys. Oceanogr. 2018, 48, 1233-1241. [CrossRef]

46. D’Asaro, E.A.; Shcherbina, A.Y.; Klymak, J.M.; Molemaker, J.; Novelli, G.; Guigand, C.M.; Haza, A.C.; Haus, B.K.; Ryan, E.H.; Jacobs, G.A. Ocean convergence and the dispersion of flotsam. Proc. Natl. Acad. Sci. USA 2018, 115, 1162-1167. [CrossRef] [PubMed]

47. Hörig, B.; Kühn, F.; Oschütz, F.; Lehmann, F. HyMap hyperspectral remote sensing to detect hydrocarbons. Int. J. Remote Sens. 2001, 22, 1413-1422. [CrossRef]

48. Kühn, F.; Oppermann, K.; Hörig, B. Hydrocarbon Index-An algorithm for hyperspectral detection of hydrocarbons. Int. J. Remote Sens. 2004, 25, 2467-2473. [CrossRef] 
49. Scafutto, R.D.M.; de Souza Filho, C.R.; de Oliveira, W.J. Hyperspectral remote sensing detection of petroleum hydrocarbons in mixtures with mineral substrates: Implications for onshore exploration and monitoring. ISPRS J. Photogramm. Remote Sens. 2017, 128, 146-157. [CrossRef]

50. Garaba, S.P.; Dierssen, H.M. An airborne remote sensing case study of synthetic hydrocarbon detection using short wave infrared absorption features identified from marine-harvested macro- and microplastics. Remote Sens. Environ. 2018, 205, 224 - 235. [CrossRef]

51. Garaba, S.P.; Aitken, J.; Slat, B.; Dierssen, H.M.; Lebreton, L.; Zielinski, O.; Reisser, J. Sensing Ocean Plastics with an Airborne Hyperspectral Shortwave Infrared Imager. Environ. Sci. Technol. 2018, 52, 11699-11707. [CrossRef]

52. Goddijn-Murphy, L.; Dufaur, J. Proof of concept for a model of light reflectance of plastics floating on natural waters. Mar. Pollut. Bull. 2018, 135, 1145-1157. [CrossRef]

53. Garaba, S.; Dierssen, H. Spectral Reference Library of 11 Types of Virgin Plastic Pellets Common in Marine Plastic Debris. Data Set. 2017. Available online https://ecosis.org/search/polymers/\%5B\%5D/0/6 (accessed on 10 June 2019).

54. Kokaly, R.F.; Clark, R.N.; Swayze, G.A.; Livo, K.E.; Hoefen, T.M.; Pearson, N.C.; Wise, R.A.; Benzel, W.M.; Lowers, H.A.; Driscoll, R.L.; et al. USGS Spectral Library Version 7; Report 1035; U.S. Geological Survey: Reston, VA, USA, 2017. [CrossRef]

55. Kou, L.; Labrie, D.; Chylek, P. Refractive indices of water and ice in the 0.65- to 2.5- $\mu \mathrm{m}$ spectral range. Appl. Opt. 1993, 32, 3531-3540. [CrossRef]

56. Transon, J.; d'Andrimont, R.; Maugnard, A.; Defourny, P. Survey of hyperspectral earth observation applications from space in the sentinel-2 context. Remote Sens. 2018, 10, 157. [CrossRef]

57. Werdell, P.J.; McKinna, L.I.W.; Boss, E.; Ackleson, S.G.; Craig, S.E.; Gregg, W.W.; Lee, Z.; Maritorena, S.; Roesler, C.S.; Rousseaux, C.S.; et al. An overview of approaches and challenges for retrieving marine inherent optical properties from ocean color remote sensing. Prog. Oceanogr. 2018, 160, 186-212. [CrossRef] [PubMed]

58. Drinkwater, R.; Rebhan, H. Sentinel-3: Mission Requirements Document; European Space Agency: Paris, France, 2007.

59. Cetnic, I.; McClain, C.R.; Werdell, P.J. (Eds.) Pre-Aerosols, Clouds, and Ocean Ecosystem (PACE) Mission Science Definition Team Report; NASA, Goddard Space Flight Center: Greenbelt, MD, USA, 2018; Volume 2.

60. Topouzelis, K.; Papakonstantinou, A.; Garaba, S.P. Detection of floating plastics from satellite and unmanned aerial systems (Plastic Litter Project 2018). Int. J. Appl. Earth Obs. Geoinf. 2019, 79, 175-183. [CrossRef]

61. Hank, T.B.; Berger, K.; Bach, H.; Clevers, J.G.; Gitelson, A.; Zarco-Tejada, P.; Mauser, W. Spaceborne imaging spectroscopy for sustainable agriculture: Contributions and challenges. Surv. Geophys. 2018, 40, 515-551. [CrossRef]

62. Giardino, C.; Brando, V.; Gege, P.; Pinnel, N.; Hochberg, E.; Knaeps, E.; Reusen, I.; Doerffer, R.; Bresciani, M.; Braga, F. Imaging spectrometry of inland and coastal waters: State of the art, achievements and perspectives. Surv. Geophys. 2018, 40, 401-429. [CrossRef]

63. Churnside, J.H.; Thorne, R.E. Comparison of airborne lidar measurements with $420 \mathrm{kHz}$ echo-sounder measurements of zooplankton. Appl. Opt. 2005, 44, 5504-5511. [CrossRef]

64. Hostetler, C.A.; Behrenfeld, M.J.; Hu, Y.; Hair, J.W.; Schulien, J.A. Spaceborne lidar in the study of marine systems. Annu. Rev. Mar. Sci. 2018, 10, 121-147. [CrossRef]

65. Raimondi, V.; Palombi, L.; Lognoli, D.; Masini, A.; Simeone, E. Experimental tests and radiometric calculations for the feasibility of fluorescence LIDAR-based discrimination of oil spills from UAV. Int. J. Appl. Earth Obs. Geoinf. 2017, 61, 46-54. [CrossRef]

66. Zhao, G.; Ljungholm, M.; Malmqvist, E.; Bianco, G.; Hansson, L.; Svanberg, S.; Brydegaard, M. Inelastic hyperspectral lidar for profiling aquatic ecosystems. Laser Photonics Rev. 2016, 10, 807-813. [CrossRef]

67. Htun, M.T. Characterization of high-density polyethylene using laser-induced fluorescence (LIF). J. Polym. Res. 2012, 19, 9823. [CrossRef]

68. Piruska, A.; Nikcevic, I.; Lee, S.H.; Ahn, C.; Heineman, W.R.; Limbach, P.A.; Seliskar, C.J. The autofluorescence of plastic materials and chips measured under laser irradiation. Lab Chip 2005, 5, 1348-1354. [CrossRef]

69. Spizzichino, V.; Caneve, L.; Colao, F.; Ruggiero, L. Characterization and discrimination of plastic materials using laser-induced fluorescence. Appl. Spectrosc. 2016, 70, 1001-1008. [CrossRef] [PubMed] 
70. Behrenfeld, M.J.; Hu, Y.; Hostetler, C.; Dall'Olmo, G.; Rodier, S.; Hair, J.W.; Trepte, C. Space-based lidar measurements of global carbon stocks. Geophys. Res. Lett. 2013, 40, 4355-4360. [CrossRef]

71. Li, X.M.; Lehner, S. Algorithm for Sea Surface Wind Retrieval From TerraSAR-X and TanDEM-X Data. IEEE Trans. Geosci. Remote Sens. 2014, 52, 2928-2939. doi:10.1109/TGRS.2013.2267780. [CrossRef]

72. Romeiser, R.; Runge, H.; Suchandt, S.; Kahle, R.; Rossi, C.; Bell, P. Quality Assessment of Surface Current Fields From TerraSAR-X and TanDEM-X Along-Track Interferometry and Doppler Centroid Analysis. IEEE Trans. Geosci. Remote Sens. 2014, 52, 2759-2772. doi:10.1109/TGRS.2013.2265659. [CrossRef]

73. Arii, M.; Koiwa, M.; Aoki, Y. Applicability of SAR to Marine Debris Surveillance After the Great East Japan Earthquake. IEEE J. Sel. Top. Appl. Earth Obs. Remote Sens. 2014, 7, 1729-1744. [CrossRef]

74. DiGiacomo, P.M.; Washburn, L.; Holt, B.; Jones, B. Coastal pollution hazards in southern California observed by SAR imagery: Stormwater plumes wastewater plumes and natural hydrocarbon seeps. Mar. Pollut. Bull. 2004, 49, 1013-1024. [CrossRef]

75. Latini, D.; Del Frate, F.; Jones, C. Multi-frequency and polarimetric quantitative analysis of the Gulf of Mexico oil spill event comparing different SAR systems. Remote Sens. Environ. 2016, 183, 26-42. [CrossRef]

76. Matthews, J.; Ostrovsky, L.; Yoshikawa, Y.; Komori, S.; Tamura, H. Dynamics and early post-tsunami evolution of floating marine debris near Fukushima Daiichi. Nat. Geosci 2017, 10, 598-603. [CrossRef]

77. Skrunes, S.; Brekke, C.; Eltoft, T. Characterization of Marine Surface Slicks by Radarsat-2 Multipolarization Features. IEEE Trans. Geosci. Remote Sens. 2014, 52, 5302-5319. [CrossRef]

78. Lekner, J.; Dorf, M.C. Why some things are darker when wet. Appl. Opt. 1988, 27, 1278-1280. [CrossRef]

79. Zhang, H.; Voss, K.J. Bidirectional reflectance study on dry, wet, and submerged particulate layers: Effects of pore liquid refractive index and translucent particle concentrations. Appl. Opt. 2006, 45, 8753-8763. [CrossRef] [PubMed]

80. Li, Z.; Guo, X. Remote sensing of terrestrial non-photosynthetic vegetation using hyperspectral, multispectral, SAR, and LIDAR data. Prog. Phys. Geogr. 2015, 40, 276-304. [CrossRef]

81. Mobley, C.D. Estimation of the remote-sensing reflectance from above-surface measurements. Appl. Opt. 1999, 38, 7442-7455. [CrossRef] [PubMed]

82. Dierssen, H.M. Hyperspectral Measurements, Parameterizations, and Atmospheric Correction of Whitecaps and Foam From Visible to Shortwave Infrared for Ocean Color Remote Sensing. Front. Earth Sci. 2019, 7, 14. [CrossRef]

83. Zhang, X.D.; Lewis, M.; Johnson, B. Influence of bubbles on scattering of light in the ocean. Appl. Opt. 1998, 37, 6525-6536. [CrossRef]

84. Knaeps, E.; Dogliotti, A.; Raymaekers, D.; Ruddick, K.; Sterckx, S. In situ evidence of non-zero reflectance in the OLCI 1020nm band for a turbid estuary. Remote Sens. Environ. 2012, 120, 133-144. [CrossRef]

85. Hu, C.M.; Feng, L.; Hardy, R.F.; Hochberg, E.J. Spectral and spatial requirements of remote measurements of pelagic Sargassum macroalgae. Remote Sens. Environ. 2015, 167, 229-246. [CrossRef]

86. Radoux, J.; Chome, G.; Jackques, D.; Waldner, F.; Bellemans, N.; Matton, N.; Lamarche, C.; d'Andrimont, R.; Defourny, P. Sentinel-2's Potential for Sub-Pixel Landscape Feature Detection. Remote Sens. 2016, 8, 488. [CrossRef]

87. Acuña-Ruz, T.; Uribe, D.; Taylor, R.; Amézquita, L.; Guzmán, M.C.; Merrill, J.; Martínez, P.; Voisin, L.; Mattar, B.C. Anthropogenic marine debris over beaches: Spectral characterization for remote sensing applications. Remote Sens. Environ. 2018, 217, 309-322. [CrossRef]

88. Guanter, L.; Brell, M.; Chan, J.C.W.; Giardino, C.; Gomez-Dans, J.; Mielke, C.; Morsdorf, F.; Segl, K.; Yokoya, N. Synergies of Spaceborne Imaging Spectroscopy with Other Remote Sensing Approaches. Surv. Geophys. 2018, 40, 657-687. [CrossRef]

89. Dierssen, H.; McManus, G.B.; Chlus, A.; Qiu, D.; Gao, B.C.; Lin, S. Space station image captures a red tide ciliate bloom at high spectral and spatial resolution. Proc. Natl. Acad. Sci. USA 2015, 112, 14783-14787. [CrossRef] [PubMed]

90. Hu, C. A novel ocean color index to detect floating algae in the global oceans. Remote Sens. Environ. 2009, 113, 2118-2129. [CrossRef]

91. Wang, M.; Hu, C.; Cannizzaro, J.; English, D.; Han, X.; Naar, D.; Lapointe, B.; Brewton, R.; Hernandez, F. Remote Sensing of Sargassum Biomass, Nutrients, and Pigments. Geophys. Res. Lett. 2018, 45, 12,359-12,367. [CrossRef] 
92. Kurekin, A.A.; Loveday, B.R.; Clements, O.; Quartly, G.D.; Miller, P.I.; Wiafe, G.; Adu Agyekum, K. Operational Monitoring of Illegal Fishing in Ghana through Exploitation of Satellite Earth Observation and AIS Data. Remote Sens. 2019, 11, 293. [CrossRef]

93. Dekker, A.G.; Pinnel, N. Feasibility Study for an Aquatic Ecosystem Earth Observing System; Committee on Earth Observation Satellites (CEOS) and Commonwealth Scientific and Industrial Research Organization: Canberra, Australia, 2018.

94. Muller-Karger, F.E.; Hestir, E.; Ade, C.; Turpie, K.; Roberts, D.A.; Siegel, D.; Miller, R.J.; Humm, D.; Izenberg, N.; Keller, M. Satellite sensor requirements for monitoring essential biodiversity variables of coastal ecosystems. Ecol. Appl. 2018, 28, 749-760. [CrossRef]

C 2019 by the authors. Licensee MDPI, Basel, Switzerland. This article is an open access article distributed under the terms and conditions of the Creative Commons Attribution (CC BY) license (http://creativecommons.org/licenses/by/4.0/). 